\title{
A WORKSHOP ON LEARNING OBJECTIVES FOR ENGINEERING FACULTY MEMBERS
}

\author{
Romkey, L; McCahan, S \\ Faculty of Applied Science and Engineering, University of Toronto \\ romkey@ecf.utoronto.ca; mccahan@mie.utoronto.ca
}

\section{INTRODUCTION}

As an initial step in preparing faculty members for the new outcomes-based accreditation process introduced by the CEAB, a pilot workshop on creating learning objectives was developed for engineering professors at the University of Toronto. As the Graduate Attributes will be mapped to individual courses within engineering programs, the need for course-based learning objectives is even more critical; although research already supports the development and use of learning objectives as an effective educational practice. .

This paper will describe the process of developing the workshop, facilitating it for the first time, and the lessons learned that were used in developing a second iteration of the workshop.

\section{WORKSHOP DEVELOPMENT AND ITERATION}

To engage engineering faculty in the new outcomes-based accreditation process, professional development is essential. As faculty members interested in engineering education and engaged in the Graduate Attributes process, we sought to develop a workshop that would provide faculty with an opportunity to discuss the new Graduate Attributes; but also with the knowledge of how to write strong learning objectives, the benefits of using learning objectives, and learning taxonomies to consider when developing learning objectives for engineering courses. Currently, some faculty write and publish a detailed set of learning objectives, while others give little or no explicit indication to the students of what is expected of them by the end of the learning experience. Our long-term goal is to support the development and use of learning objectives across our faculty, both to support the Graduate Attributes process, and as a good educational practice more generally.

It was decided that the workshop would be most effective if instructors were encouraged to take their current course content and essentially classify it using the levels of learning provided by a learning taxonomy, followed by the writing of their own set of learning objectives. To achieve this goal, appropriate learning taxonomies needed to be selected. Bloom's Cognitive Taxonomy [1], a commonly used learning taxonomy associated with learning in the cognitive domain, was selected to represent learning associated with the various facts, principles and theories in an undergraduate engineering degree. Affective [2] and Psychomotor [3] taxonomies were also selected as supplemental options, to help instructors articulate learning objectives associated with moral development, ethical development and other attitudinal changes; and areas of manual and physical skills, respectively. An interpersonal taxonomy [4] was used to represent the learning that happens while working in a team environment, regardless of discipline or context.

While these taxonomies are useful in helping faculty describe expectations around learning, these taxonomies didn't allow us to fully describe engineering processes; such as problem solving and engineering design. Therefore, using Miller's Pyramid from the medical field as a model [5], a procedural taxonomy was developed. The taxonomy demonstrates the progression from being able to describe, for example, an engineering design process, to the ability to naturalize, or be able to select problem-solving tools and design methods to frame and solve a problem in an authentic context.

The workshop plan challenged instructors to not only develop a set of learning objectives, but to also consider how their objectives are assessed, and how they relate to the 12 Graduate Attributes. Finally, information was provided to instructors about how a preliminary committee in our Faculty envisioned the Graduate Attributes process, and how the development of course-based learning objectives fits into that process.

\section{WORKSHOP OUTCOMES}

A key challenge discovered through the process of facilitating the workshop was that of introducing a new lexicon of learning and instructional design. Terms such as "cognitive" were new to many of our faculty participants, but even the meaning of terms like "knowledge" were met with different and unexpected interpretations. The issue becomes especially confusing when one considers that "knowledge" has a specific meaning within the context of Bloom's Taxonomy, for example, but is used more generally in an everyday context. In our presentation of the workshop material, we had our own understanding of terms like "content" and "curriculum", but the subtle differences between these terms were not as clear to those new to the educational lexicon, who sometimes found the "education speak" a little frustrating. In the second iteration of the workshop, we emphasized the use and definition of specific terms, and used the terminology itself as a running workshop outline, to help mitigate some of the challenges.

The engineering faculty raised some excellent questions with respect to the number of learning objectives to write for their courses, and at what level objectives needed to be developed. In the second iteration of the workshop, we emphasized the differences between "global" and "instructional" objectives, to demonstrate how faculty could write learning objectives at a course or lecture level, for example. When it came to the learning taxonomies, there was some confusion about whether the taxonomies should be considered discrete. For example, our participants became confused when they felt some of their course content was relevant to both the "cognitive" and "process" taxonomies. We realized we needed to share the learning taxonomies as a set of tools, in some cases representing overlapping knowledge and skills, that could be used to represent their courses. To emphasize this, we removed the "classification of content" in the second workshop iteration, and encouraged the instructors to move directly to the development of sample learning objectives.

In the engineering tradition, the provision of examples is important, and in the first iteration of the workshop, while we provided examples of learning objectives, the instructors asked for examples of how course learning objectives would be assessed and mapped to the Graduate Attributes. In the second iteration of the workshop, we were able to provide a specific example of how two Graduate Attributes, communication and investigation, could be mapped to a fourth year thesis course in one of our engineering programs.

\section{DISCUSSION}

The development of learning objectives is an important part of working towards the implementation of the Graduate Attributes; to assess learning and program quality, we must be explicit and specific about what we want our students to learn. The introduction of the Engineering Graduate Attributes provides an opportunity to encourage the implementation of a good educational practice. In the second iteration of the workshop, with more work completed on defining the Graduate Attribute process, we were better able to contextualize the importance of developing learning objectives within this process; and with refinements in the presentation of vocabulary, the use of examples and a different explanation of the learning taxonomies, we were better able to reach and encourage the engineering faculty.

In addition to the concerns raised above, the participants have raised interesting questions about how learning objectives really make a difference in educational quality, and whether they might create a limit in the student's mind of what they should be learning. We hope that through the workshop, and particularly the second iteration of the workshop, we have been able to demonstrate that learning objectives create a sense of transparency, but should not be viewed as the "maximum level of learning" - in fact, if students are able to conceptualize and demonstrate learning objectives beyond what the instructor has provided, we might say that we are making some headway in our life-long learning attribute.

\section{REFERENCES}

1. Bloom BS. Taxonomy of Educational Objectives, Handbook I: The Cognitive Domain. New York, NY: David McKay Co Inc., 1956. 2. Krathwohl, DR, Bloom, BS, \& Masia, BB. Taxonomy of Educational Objectives, the Classification of Educational Goals. Handbook II: Affective Domain. New York, NY: David McKay Co., Inc., 1973. 3. R. H. Dave, as reported in R. J. Armstrong et al., Developing and Writing Behavioral Objectives. Tucson, AZ: Educational Innovators Press, 1970.

4. C. Vinson. Learning Domains and Delivery of Instruction. [Online]. Available: http://pixel.fhda.edu/hybrid/learning_domain.html. 5. G. E. Miller. Acad. Med., 1990; 65: 63-67. 